\title{
DECOMPOSIÇÃO CATALÍTICA DE ÓXIDOS DE NITROGÊNIO
}

\author{
Julia María Díaz Cónsul, Daniel Thiele, Renato Cataluña Veses e Ione Maluf Baibich* \\ Instituto de Química, Universidade Federal do Rio Grande do Sul, Av. Bento Gonçalves, 9500, 91501-970 Porto Alegre - RS \\ Rogério Marcos Dallago \\ Departamento de Química, Universidade Regional Integrada do Alto Uruguai e das Missões, Campus Erechim, \\ Av. Sete de Setembro, 1621, 99700-000 Erechim - RS
}

Recebido em 3/2/03; aceito em 19/9/03

\begin{abstract}
CATALYTIC DECOMPOSITION OF NITROGEN OXIDES. Contaminant gases in the atmosphere constitute an important problem to be solved in the world. The NOx gases produced as a consequence of engine high temperatures are deleterious to environment and human health, as they promote acid rain and can act in the same way as freons in the destruction of the ozone layer in the stratosphere. In this review, three way and selective reduction catalysts for decomposition of these contaminant gases are described. Details about conditions and problems, such as catalyst poisoning, and the search for new catalysts are shown.
\end{abstract}

Keywords: $\mathrm{NO}_{\mathrm{x}}$; $\mathrm{NO}$ selective reduction; three-way catalyst.

\section{INTRODUÇÃO}

O ar, tal como a água e o solo, é um recurso indispensável na Terra. Através de ciclos naturais, seus constituintes são consumidos ou reciclados. A atmosfera tem assim, uma certa capacidade depuradora que, em condições naturais, garante a eliminação dos materiais nela descarregados pelos seres vivos.

O desequilíbrio deste sistema natural autoregulado conduz à acumulação na atmosfera de substâncias nocivas à vida, fazendo nascer a necessidade de uma ação de prevenção ou de saneamento artificial que, conforme o caso, seja capaz de assegurar a manutenção da qualidade do ar.

Os óxidos de nitrogênio $\left(\mathrm{NO}_{\mathrm{x}}\right)$ provêm de fontes naturais, tais como atividade vulcânica, queima de biomassa (fundamentalmente queima de florestas provocada por fontes naturais) e atividade bacteriana. Porém, o tráfego automobilístico, assim como a combustão em caldeiras e fornos, constituem as principais fontes de formação destes óxidos, que são considerados importantes contaminantes ambientais, devido à sua participação na chuva ácida, responsável pela destruição das florestas, assim como no "smog" fotoquímico, que é intensamente irritante aos olhos e às mucosas ${ }^{1}$. As emissões de $\mathrm{NO}_{\mathrm{x}}$ no mundo são de 10 milhões de toneladas por ano, provenientes de fontes naturais (1 milhão nos Estados Unidos) e 40 milhões de toneladas por ano, de fontes antropogênicas (6 milhões nos Estados Unidos) oriundas principalmente dos processos de combustão, tais como as emissões automotivas ${ }^{2}$.

Os catalisadores são necessários para a decomposição desses gases contaminantes. Os catalisadores chamados de três vias permitem o controle da emissão de $\mathrm{NO}_{\mathrm{x}}$ dos motores de gasolina convencionais, sempre que a relação ar/combustível seja mantida perto da estequiométrica. Esses catalisadores são formados por um suporte, geralmente alumina modificada com promotores como o óxido de cério, zircônia e com cério/zircônia, e metais de transição, sendo os mais utilizados Pt e Rh. A alumina, por sua vez, é suportada sobre um monolito cerâmico, geralmente de cordierita ${ }^{3}$.
A eliminação de $\mathrm{NO}_{x}$ em condições oxidantes, que ocorre nos processos de combustão em caldeiras e fornos, assim como nos motores de queima pobre ("lean-burn engines") e motores a diesel, não é efetiva utilizando catalisadores de três vias. Normalmente, é utilizado um sistema de redução catalítica seletiva com catalisadores à base de pentóxido de vanádio, óxido de titânio e óxido de tungstênio $\left(\mathrm{V}_{2} \mathrm{O}_{5}-\mathrm{TiO}_{2}-\mathrm{WO}_{3}\right)$ que emprega amônia $\left(\mathrm{NH}_{3}\right)$ como agente redutor. Existem inúmeros inconvenientes na utilização deste processo, tais como o elevado custo de operação e a emissão ao ambiente de excesso de $\mathrm{NH}_{3}$.

Estes inconvenientes mostram que o controle das emissões de $\mathrm{NO}_{x}$ é um problema não resolvido, que faz com que muitos especialistas da área, no mundo inteiro, continuem trabalhando na busca de novas alternativas.

Este trabalho tem por objetivo revisar os principais aspectos relacionados com a contaminação atmosférica provocada pelos óxidos de nitrogênio e a decomposição catalítica dos mesmos, como uma alternativa para sua transformação em produtos não tóxicos ao meio ambiente.

\section{POLUIÇÃO ATMOSFÉRICA}

Desde a descoberta do fogo, a poluição atmosférica vem aumentando a cada ano. A quantidade de gases contaminantes e de partículas lançadas na atmosfera torna preocupante o futuro do ar no planeta.

Os constituintes gasosos da atmosfera e seus níveis, quando o ar é considerado limpo, são mostrados na Tabela 1. Problemas de poluição atmosférica estão relacionados com o aumento nas concentrações daqueles compostos considerados prejudiciais, como por exemplo $\mathrm{CO}, \mathrm{NO}_{x}$, hidrocarbonetos, $\mathrm{SO}_{\mathrm{x}}$ e compostos halogenados ${ }^{4}$.

Os poluentes atmosféricos podem apresentar-se nas formas de partículas sólidas, aerosóis ou gases e, geralmente, dividem-se em dois grupos distintos: $i$ ) poluentes primários $\left(\mathrm{CO}, \mathrm{NO}_{x}\right.$, $\mathrm{HCs}$ e material particulado), emitidos diretamente de fontes identificáveis; ii) poluentes secundários (ozônio, $\mathrm{HNO}_{3}, \mathrm{H}_{2} \mathrm{O}_{2}$, nitrato de peróxiacila, etc), produzidos na atmosfera pela interação entre dois ou mais poluentes primários, ou por reação com os constituintes atmosféricos normais, com ou sem fotoativação ${ }^{5-8}$, tendo nos óxidos de nitrogênio $\left(\mathrm{NO}_{\mathrm{x}}\right)$ um de seus principais precursores. 
Tabela 1. Constituintes gasosos da atmosfera. Adaptada da ref. 4

\begin{tabular}{cccccc}
\hline Constituinte & Composição $(\%, \mathrm{v} / \mathrm{v})$ & Constituinte & Composição (ppb, v/v) & Constituinte & Composição (ppb, v/v) \\
\hline $\mathrm{N}_{2}$ & 78,1 & $\mathrm{Kr}$ & 1000 & $\mathrm{NH}_{3}$ & 6 \\
$\mathrm{O}_{2}$ & 20,9 & $\mathrm{H}_{2}$ & 500 & $\mathrm{SO}_{2}$ & 2 \\
$\mathrm{Ar}$ & 0,934 & $\mathrm{~N}_{2} \mathrm{O}$ & 300 & $\mathrm{CH}_{3} \mathrm{Cl}$ & 0,5 \\
$\mathrm{CO}_{2}$ & 0,033 & $\mathrm{CO}$ & 100 & $\mathrm{C}_{2} \mathrm{H}_{4}$ & 0,2 \\
$\mathrm{Ne}$ & 0,002 & $\mathrm{Xe}$ & 90 & $\mathrm{CCl}_{4}$ & 0,1 \\
$\mathrm{He}$ & 0,0005 & $\mathrm{O}$ & 40 & $\mathrm{CCl}_{3} \mathrm{~F}$ & 0,1 \\
$\mathrm{CH}_{4}$ & 0,0002 & $\mathrm{NO}_{2}+\mathrm{NO}$ & $10-0,001$ & & \\
\hline
\end{tabular}

\section{Produção de $\mathrm{NO}_{x}$ na atmosfera}

Os óxidos de nitrogênio, denominados $\mathrm{NO}_{x}$, são o óxido nítrico (NO), o óxido nitroso $\left(\mathrm{N}_{2} \mathrm{O}\right)$ e o dióxido de nitrogênio $\left(\mathrm{NO}_{2}\right)$.

Os $\mathrm{NO}_{x}$ podem ser formados naturalmente mediante transformações microbianas no solo e por descargas elétricas na atmosfera $(\text { raios })^{9}$. Com relação às emissões de origem antropogênica, estas resultam principalmente da queima, a altas temperaturas, de combustíveis fósseis em instalações fixas ou em veículos automotores ${ }^{10-11}$. Entre os $\mathrm{NO}_{x}$, o NO e o $\mathrm{NO}_{2}$ são os que apresentam relevância quanto à poluição ambiental ${ }^{6,12,13}$. Destes, mais de $95 \%$ das emissões estão sob a forma de $\mathrm{NO}^{13}$.

\section{Óxido nitroso $\left(\mathrm{N}_{2} \mathrm{O}\right)$}

O óxido nitroso é o óxido de nitrogênio mais abundante na atmosfera (Tabela 1), sendo estável e quimicamente não reativo. Em condições ambientais, é formado pela alga azul-verde e pela bactéria Rhizobium, ativa nos nódulos de ervilhas, feijões e outros legumes. Pelo homem, é introduzido no ambiente através dos motores de combustão interna, termoelétricas e indústrias de fertilizantes ${ }^{1}$.

Este óxido não é normalmente considerado poluente, embora tenha um efeito sobre as concentrações de ozônio estratosférico, devido à sua capacidade de reagir com o oxigênio atômico e formar óxido nítrico ${ }^{14}$ :

$\mathrm{N}_{2} \mathrm{O}+\mathrm{O}^{\cdot} \longrightarrow 2 \mathrm{NO}$

Em concentrações adequadas, o óxido nitroso, conhecido como gás hilariante, pode ser utilizado como anestésico ${ }^{15}$. Por sua baixa toxicidade e pela euforia que provocava, $\mathrm{o}_{2} \mathrm{O}$ foi usado como entorpecente, levando seus usuários, em alguns casos, à morte por hipoxia (falta de oxigênio). Atualmente, o gás é empregado como agente formador de espumas, gerando outro problema: quando liberado para a atmosfera, reage e acaba ajudando a destruir a camada de ozônio ${ }^{16}$.

\section{Óxido nítrico $(\mathrm{NO})$}

$\mathrm{O}$ óxido nítrico é introduzido no ambiente, principalmente pelos gases de escape dos automóveis, em conseqüência da alta temperatura.

O NO puro é praticamente inofensivo, mas pode oxidar-se facilmente formando dióxido de nitrogênio, através de reação com oxigênio, com ozônio e até com radicais peróxidos presentes na atmosfera $^{1}$ :

$$
\begin{aligned}
& \mathrm{NO}+\mathrm{RO}_{2} \cdot \longrightarrow \mathrm{NO}_{2}+\mathrm{RO} \\
& \mathrm{NO}+\mathrm{O}_{3} \longrightarrow \mathrm{NO}_{2}+\mathrm{O}_{2} \\
& 2 \mathrm{NO}+\mathrm{O}_{2} \longrightarrow 2 \mathrm{NO}_{2}
\end{aligned}
$$

O NO também pode diminuir as concentrações de ozônio na estratosfera, contribuindo com a destruição da camada de ozônio ${ }^{14}$. O $\mathrm{O}_{3}$ na estratosfera atua como filtro solar, impedindo ou reduzindo a passagem da radiação ultravioleta do sol, prejudicial à saúde humana, sendo a principal causa do câncer de pele. Na troposfera, a presença de ozônio em concentrações elevadas é prejudicial (concentrações maiores que 20-50 ppb) devido a seu alto poder oxidante, levando à formação de radicais nitrato e estes, por sua vez, reagem rapidamente com a luz solar'

$\mathrm{NO}+\mathrm{O}_{3} \longrightarrow \mathrm{NO}_{2}+\mathrm{O}_{2}$

$\mathrm{NO}_{2}+\mathrm{O}_{3} \longrightarrow \mathrm{NO}_{3}+\mathrm{O}_{2}$

$\mathrm{NO}_{3}+\mathrm{hv} \longrightarrow \mathrm{NO}+\mathrm{O}_{2}$

$\mathrm{NO}_{3} \cdot \mathrm{hv} \longrightarrow \mathrm{NO}_{2}+\mathrm{O}^{\cdot}\left({ }^{3} \mathrm{P}\right)$

$\mathrm{O}$ ozônio é formado fotoquímicamente pela fotólise do $\mathrm{NO}_{2}$ e, por sua vez, reage rapidamente com $\mathrm{NO}^{2}$ :

$\mathrm{NO}_{2}+\mathrm{hv} \longrightarrow \mathrm{NO}+\mathrm{O}^{\cdot}\left({ }^{3} \mathrm{P}\right)$

$\mathrm{O}^{\cdot}\left({ }^{2} \mathrm{P}\right)+\mathrm{O}_{2}+\mathrm{M} \longrightarrow \mathrm{O}_{3}+\mathrm{M} \quad(\mathrm{M}=\mathrm{ar})$

$\mathrm{NO}+\mathrm{O}_{3} \longrightarrow \mathrm{NO}_{2}+\mathrm{O}_{2}$

Estas reações resultam em um fotoequilíbrio entre $\mathrm{NO}, \mathrm{NO}_{2}$ e $\mathrm{O}_{3}$.

No entanto, ocorre a degradação de compostos orgânicos voláteis (COVs, principalmente metano, isoprenos, monoterpenos, sesquiterpenos e compostos oxigenados como metanol e 2-metil-3buten-2-ol). Estes são introduzidos na troposfera pelas plantas, por fontes de combustão, estocagem e transporte de combustível, por emissões industriais, etc., levando à formação de radicais $\mathrm{RO}_{2}{ }^{\circ} \mathrm{e} \mathrm{HO}_{2} \cdot$ que reagem com o $\mathrm{NO}$ oxidando-o a $\mathrm{NO}_{2}$ que, posteriormente, fotolisa para formar $\mathrm{O}_{3}^{2}$ :

$\mathrm{HO}_{2} \cdot \mathrm{NO} \longrightarrow{ }^{\cdot} \mathrm{OH}+\mathrm{NO}_{2}$

$\mathrm{RO}_{2}^{\cdot}+\mathrm{NO} \longrightarrow \mathrm{RO}^{*}+\mathrm{NO}_{2}$

Por outro lado, a fotólise do ozônio na presença de vapor de água é a maior fonte de radicais hidroxila na troposfera (reações 1215). Outras fontes de radicais $\mathrm{OH}$ são a fotólise do ácido nitroso, a fotólise do formaldeído e de outros compostos carbonílicos, na presença de NO. Os radicais $\mathrm{OH}$ são a espécie ativa chave na troposfera, reagindo com todos os compostos orgânicos, exceto os clorofluorcarbonos.

$$
\begin{array}{ll}
\mathrm{O}_{3}+\mathrm{h} v \longrightarrow \mathrm{O}_{2}+\mathrm{O}^{*}\left({ }^{1} \mathrm{D}\right) & (\lambda \leq 335 \mathrm{~nm}) \\
\mathrm{O}^{*}\left({ }^{1} \mathrm{D}\right)+\mathrm{M} \longrightarrow \mathrm{O}^{*}\left({ }^{3} \mathrm{P}\right)+\mathrm{M} & \left(\mathrm{M}=\mathrm{N}_{2}, \mathrm{O}_{2}\right) \\
\mathrm{O}^{*}\left({ }^{3} \mathrm{P}\right)+\mathrm{O}_{2}+\mathrm{M} \longrightarrow \mathrm{O}_{3}+\mathrm{M} & (\mathrm{M}=\mathrm{ar}) \\
\mathrm{O}^{*}\left({ }^{1} \mathrm{D}\right)+\mathrm{H}_{2} \mathrm{O} \longrightarrow 2 \cdot \mathrm{OH} &
\end{array}
$$

Na ausência de NO, ou em concentrações muito baixas, as reações do ozônio com radicais hidroxila e peróxido contribuem para a decomposição do ozônio troposférico:

$\cdot \mathrm{OH}+\mathrm{O}_{3} \longrightarrow \mathrm{HO}_{2}^{\cdot}+\mathrm{O}_{2}$
$\mathrm{HO}{ }^{\cdot}+\mathrm{O}_{3} \longrightarrow \mathrm{OH}^{2}+2 \mathrm{O}_{2}$ 
A formação fotoquímica de ozônio e a sua decomposição fotoquímica na troposfera dependem da concentração de NO e estão determinadas pela velocidade de reação dos radicais $\mathrm{HO}_{2}{ }^{\cdot}$ e $\mathrm{RO}_{2}{ }^{*}$ com $\mathrm{NO}^{2}$.

$\mathrm{HO}_{2} \cdot+\mathrm{NO} \longrightarrow \mathrm{OH}+\mathrm{NO}_{2}$
$\mathrm{HO}_{2}^{\cdot}+\mathrm{HO}_{2} \longrightarrow \mathrm{H}_{2} \mathrm{O}_{2}+\mathrm{O}_{2}$
$\mathrm{HO}_{2}^{\cdot}+\mathrm{O}_{3} \longrightarrow \mathrm{OH}+2 \mathrm{O}_{2}$
$\mathrm{RO}_{2}^{\cdot}+\mathrm{NO} \longrightarrow \mathrm{RO}^{\cdot}+\mathrm{NO}_{2}$
$\mathrm{RO}_{2}^{\cdot}+\mathrm{HO}_{2} \longrightarrow \mathrm{ROH}+\mathrm{O}_{2}$

O óxido nítrico participa também em diversas funções biológicas, como neurotransmissor e vasodilatador. Em pequenas concentrações é utilizado para tratamento da impotência.

\section{Dióxido de nitrogênio $\left(\mathrm{NO}_{2}\right)$}

$\mathrm{O}$ dióxido de nitrogênio é o vilão dos óxidos de nitrogênio. $\mathrm{O}$ $\mathrm{NO}_{2}$ é um gás muito tóxico. A pessoa atingida sente imediatamente ardência nos olhos, no nariz e nas mucosas em geral. $\mathrm{O} \mathrm{NO}_{2}$ reage com todas as partes do corpo expostas ao ar, pele e mucosas provocando lesões celulares. Os epitélios (revestimentos celulares) que mais sofrem são aqueles das vias respiratórias, ocorrendo degenerações celulares e inflamações no sistema respiratório, desde o nariz até a profundidade dos alvéolos pulmonares.

Em caso de intoxicação grave, a inalação provoca edema pulmonar, hemorragias alveolares e insuficiência respiratória, causando morte. Se a exposição for aguda, porém não fatal, aparecerão traqueítes e bronquites crônicas, efisema pulmonar (dilatação anormal dos alvéolos), espessamento da barreira alvéolo-capilar (dificuldades nas trocas gasosas que ocorrem nos pulmões: $\mathrm{CO}_{2}$ por $\mathrm{O}_{2}$ ) e broncopneumonias químicas ou infecciosas.

O dióxido de nitrogênio pode reagir também com radicais hidróxido provenientes, principalmente, da água e formar ácido nítrico. Este comportamento é análogo ao do dióxido de enxofre que forma ácido sulfúrico, sendo esses dois óxidos os principais responsáveis pelo fenômeno da chuva ácida ${ }^{17}$.

Os óxidos de nitrogênio também participam na formação do "smog" fotoquímico que é um aerosol branco, irritante aos olhos e mucosas, constituído por produtos resultantes da interação de compostos orgânicos e óxidos de nitrogênio, entre eles aldeídos, nitratos de alquila, ozônio e nitrato de peróxiacila (PAN) $)^{10,18-21}$.

Como foi mostrado anteriormente (reações 12-15), a fotólise do ozônio gera radicais ${ }^{\circ} \mathrm{OH}$, que reagem com os hidrocarbonetos dando lugar à formação de radicais peróxialquila ${ }^{2,19}$ :

$\mathrm{RH}+{ }^{\circ} \mathrm{OH} \mathrm{R}^{\bullet}+\mathrm{H}_{2} \mathrm{O}$

$\mathrm{R}^{\cdot}+\mathrm{O}_{2} \mathrm{RO}_{2} \cdot$

Os radicais ${ }^{\circ} \mathrm{OH}$ reagem também com aldeídos formando radicais acila e peróxiacila, que reagem posteriormente com $\mathrm{NO}_{2}$, dando lugar ao $\mathrm{PAN}^{19}$ :

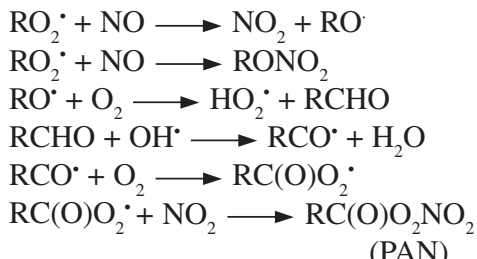

O nitrato de peróxiacila (PAN) é um dos produtos mais tóxicos formados, atuando como reservatório de óxidos de nitrogênio devido à elevada estabilidade na temperatura da baixa troposfera ${ }^{19}$. Sua formação aumenta consideravelmente, quando as emissões veiculares são originadas por automóveis movidos à álcool. O álcool favorece também a formação de aldeídos, preferencialmente acetaldeído ${ }^{6,9,10,22,23}$.

Desta maneira, o esforço de cientistas e pesquisadores de todo o mundo tem-se concentrado na busca de alternativas para decompor esses gases, sendo a decomposição via catalítica uma alternativa promissora.

\section{DECOMPOSIÇÃO CATALÍTICA DE ÓXIDOS DE NITROGÊNIO}

Os catalisadores, utilizados nos escapamentos de automóveis e na indústria, possuem a finalidade de diminuir a poluição causada pela emissão de gases nocivos à saúde, produzidos no interior do motor do automóvel e nos processos de combustão em caldeiras e fornos.

O catalisador acelera as reações químicas que transformam os poluentes (monóxido de carbono, óxidos de nitrogênio e hidrocarbonetos) em compostos menos prejudiciais ao meio ambiente (dióxido de carbono, água e nitrogênio). De um modo simplificado, as reações que ocorrem são as seguintes ${ }^{18}$ :

$$
\begin{aligned}
& 2 \mathrm{CO}+\mathrm{O}_{2} \longrightarrow 2 \mathrm{CO}_{2} \\
& 2 \mathrm{C}_{2} \mathrm{H}_{6}+7 \mathrm{O}_{2} \longrightarrow 4 \mathrm{CO}_{2}+6 \mathrm{H}_{2} \mathrm{O} \\
& 2 \mathrm{NO}_{2}+4 \mathrm{CO} \longrightarrow \mathrm{N}_{2}+4 \mathrm{CO}_{2}
\end{aligned}
$$

A decomposição dos gases $\mathrm{NO}_{\mathrm{x}}$ pode ser feita por dois tipos de catalisadores, os chamados catalisadores de três vias e os utilizados para a redução catalítica seletiva, conforme será detalhado a seguir.

\section{Catalisadores de três vias}

O uso de conversores catalíticos automotivos teve início nos Estados Unidos, em meados da década de 70, para satisfazer uma legislação (criada no final dos anos 60), que restringia as emissões de origem veicular ${ }^{24}$

Inicialmente, utilizavam-se catalisadores de oxidação, compostos principalmente por Pd e Pt suportados sobre alumina de elevada área superficial, com promotores e estabilizantes adicionados ao sistema. Estes catalisadores regulam, basicamente, as emissões de $\mathrm{CO}$ e hidrocarbonetos não-reagidos (HCs) e são ativos também na redução dos $\mathrm{NO}_{\mathrm{x}}$. As emissões de $\mathrm{NO}_{\mathrm{x}}$ eram controladas empregando-se misturas pobres, ou seja, com uma elevada relação ar/combustível e diminuindo-se as temperaturas de combustão, mediante recirculação dos gases de exaustão ${ }^{25}$. A partir daí, pressionadas por diversas organizações de caráter ambiental, as legislações foram se tornando cada vez mais restritas em relação à qualidade e aos níveis de emissões toleráveis, gerando a necessidade do desenvolvimento de catalisadores capazes de alcançar, não apenas os valores padrões para a remoção de $\mathrm{CO}$ e HCs, mas também, de remoção dos $\mathrm{NO}_{\mathrm{x}}{ }^{25}$.

Para se adaptar às novas necessidades ambientais, surgiram catalisadores bimetálicos de Pd ou Pt. Utilizando-se um segundo elemento nesses catalisadores, aumentou-se a capacidade de decomposição dos gases, podendo estes atuarem na oxidação de $\mathrm{CO}$ e HCs e na redução de $\mathrm{NO}_{x}$. A escolha do ródio (Rh), que continua sendo utilizado até hoje, foi determinada levando-se em consideração a elevada capacidade desse elemento (superior a qualquer outro) de reduzir $\mathrm{NO}_{x}$ a $\mathrm{N}_{2}$, com baixa formação de $\mathrm{NH}_{3}$, em presença de $\mathrm{H}_{2}^{26-28}$.

Assim surgiram os catalisadores de três vias, compostos por uma mistura de Rh, Pt e/ou Pd, capazes de minimizar a níveis aceitáveis, e até mesmo eliminar, os principais contaminantes $\left(\mathrm{NO}_{x}, \mathrm{CO}\right.$ e $\left.\mathrm{HCs}\right)$ presentes nos sistemas de exaustão dos automóveis. A princípio, os 
catalisadores de três vias foram utilizados em conjunto com os catalisadores de oxidação, nos chamados catalisadores de leito duplo. Nestes sistemas, o motor trabalhava em condições ricas em combustíveis para facilitar a reação de redução dos $\mathrm{NO}_{x}$ no primeiro leito catalítico, constituído pelo catalisador de três vias. A seguir, injetava-se ar na corrente de exaustão, para obter a combustão total do $\mathrm{CO}$ e $\mathrm{HCs}$ no segundo leito, constituído por um catalisador de oxidação (Pt e/ou Pd). Somente no início da década de 80 , os catalisadores de três vias começaram a ser utilizados em um único leito obtendo-se, assim, uma conversão simultânea de $\mathrm{CO}$, HCs e $\mathrm{NO}_{\mathrm{x}}{ }^{24,29-31}$. O comportamento de um catalisador de três vias para uma composição de alimentação fixa é mostrado na Figura 1.

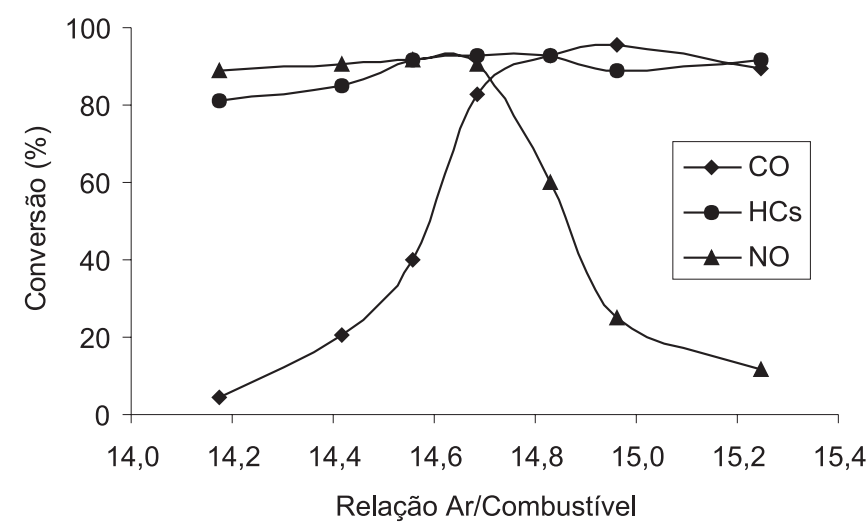

Figura 1. Comportamento de um catalisador de três vias: 0,042\% Pt e $0.018 \%$ Rh sobre alumina. Eficiência medida a $550{ }^{\circ} \mathrm{C}$ e $52000 \mathrm{~h}^{-1}$, com uma composição de alimentação fixa. Adaptada da ref. 29

O Pd tem sido amplamente estudado devido a seu baixo custo e elevada disponibilidade, em relação à $\mathrm{Pt}$ e ao $\mathrm{Rh}$. Este elemento, em condições de operação nos catalisadores de três vias, tem alta capacidade de reduzir os óxidos de nitrogênio em presença de $\mathrm{O}_{2}$, além de oxidar CO. No entanto, na presença de hidrocarbonetos sua capacidade de remoção de NO, em condições redutoras, é inferior à apresentada por catalisadores contendo ródio, devido a um envenenamento causado pelos $\mathrm{HCs}^{24,26}$. Esse problema pode ser solucionado através da incorporação de outro metal ${ }^{26,32-34}$. A Figura 2 compara resultados de $\mathrm{Pd}$ com um catalisador de $\mathrm{Pt} / \mathrm{Rh}^{28}$.

No contexto da catálise ambiental, a pesquisa nesta área foi marcada pela busca de sistemas catalíticos alternativos, com metais que substituam o ródio (devido à incompatibilidade entre sua reser-

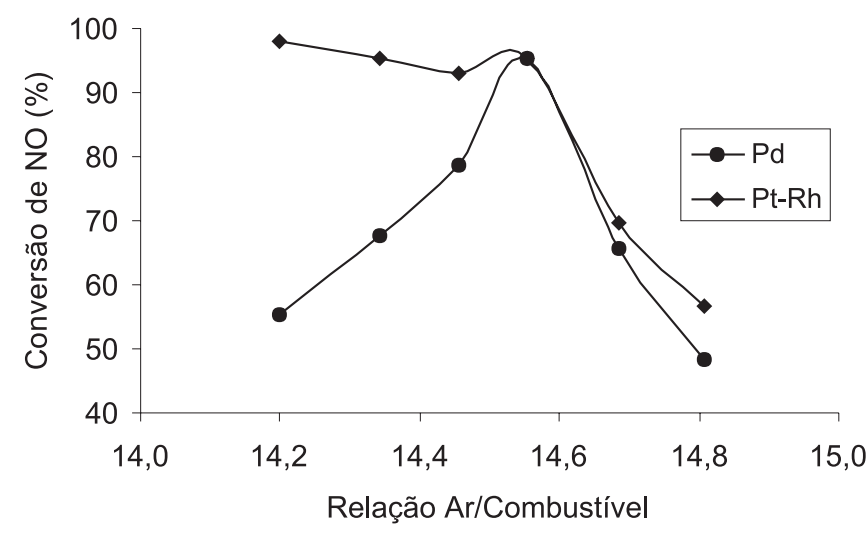

Figura 2. Conversão de NO sobre catalisadores de Pd (56 g/ft $\left.\mathrm{t}^{3}\right)$ e Pt-Rh $\left(5: 1 ; 20 \mathrm{~g} / \mathrm{ft}^{3}\right)$ a $450{ }^{\circ} \mathrm{C}$ e $30000 \mathrm{~h}^{-1}$, previamente submetidos a provas de envelhecimento (25000 milhas). Adaptada da ref. 29 va mundial, a demanda requerida e o alto custo), com atividade para a remoção de poluentes atmosféricos equivalente à apresentada pelos atuais catalisadores de três vias.

Gandhi $e$ colaboradores ${ }^{32,33}$ demonstraram o potencial oferecido por diferentes sistemas bimetálicos: $\mathrm{Pd}-\mathrm{W} / \mathrm{Al}_{2} \mathrm{O}_{3}, \mathrm{Pd}-\mathrm{Mo} / \mathrm{Al}_{2} \mathrm{O}_{3}$ e Pt$\mathrm{Mo} / \mathrm{Al}_{2} \mathrm{O}_{3}$, onde ambos os elementos (Mo e W), aparecem como potenciais substitutos do ródio, para eliminar $\mathrm{NO}_{\mathrm{x}}$ empregando diferentes agentes redutores ( $\mathrm{HCs}, \mathrm{CO}$ e $\mathrm{H}_{2}$ ). Esses autores observaram que a intensidade do efeito promotor do Mo apresentava uma significativa redução quando sua quantidade diminuía de $2 \%$ para $0,3 \%$, sugerindo a necessidade do contato entre os metais Pt-Mo e Pd-Mo. A existência de interações bimetálicas fica refletida a partir dos resultados obtidos nos ensaios de redução à temperatura programada. Tais interações facilitariam a remoção do oxigênio superficial das formas $\mathrm{MoO}_{3}$ dispersas, formando uma superfície complexa $\mathrm{Pt}^{\circ}-\mathrm{Mo}^{4+}$, com atividade e seletividade similares ao catalisador $\mathrm{Rh} / \mathrm{Al}_{2} \mathrm{O}_{3}$, na redução de $\mathrm{NO}+\mathrm{H}_{2}$. Outra informação importante é que elevadas concentrações conduziam a perdas significativas por volatilização de suas fases $\mathrm{MoO}_{3}$ e $\mathrm{WO}_{3}$, em condições oxidantes e a temperaturas superiores a $700{ }^{\circ} \mathrm{C}$. Esse problema, segundo os autores, poderia ser minimizado trabalhando com baixos teores destes elementos, de modo a assegurar sua fixação ao suporte.

Halasz e colaboradores ${ }^{34-36}$ avaliaram a redução catalítica de NO com $\mathrm{CO}$ e/ou $\mathrm{H}_{2}$ sobre catalisadores PdO- $\mathrm{MoO}_{3} / \gamma-\mathrm{Al}_{2} \mathrm{O}_{3}$, com distintos teores de molibdênio. Segundo os autores, a diferença de atividade e seletividade entre ambos os sistemas, $\mathrm{PdO} / \gamma-\mathrm{Al}_{2} \mathrm{O}_{3}$ e $\mathrm{PdO}-$ $\mathrm{MoO}_{3} / \gamma-\mathrm{Al}_{2} \mathrm{O}_{3}$, evidencia a existência de um efeito do Mo, mesmo a baixas concentrações.

A influência do precursor de Pd na redutibilidade do Mo em sistemas $\mathrm{Pd}-\mathrm{MoO}_{3} / \mathrm{Al}_{2} \mathrm{O}_{3}$ foi estudada por Schmal e colaboradores ${ }^{37}$. Esses autores observaram, por ensaios de redução à temperatura programada, que a adição de paládio promove a redução do $\mathrm{Mo}^{+6}$ para $\mathrm{Mo}^{+4}$. Neste mesmo trabalho, baseando-se na capacidade de adsorção de $\mathrm{NO}$ e/ou $\mathrm{CO}$ por estes sistemas, concluiu-se que a seletividade da dissociação de $\mathrm{NO}$ a $\mathrm{N}_{2}+\mathrm{N}_{2} \mathrm{O}$, nos catalisadores $\mathrm{Pd}-\mathrm{Mo} / \mathrm{Al}_{2} \mathrm{O}_{3}$, está diretamente vinculada à quantidade de óxido parcialmente reduzido. A ação catalítica destes sistemas bimetálicos, sobre a reação NO + $\mathrm{CO}$, foi atribuída pelos autores a um mecanismo bifuncional: após a adsorção e dissociação do $\mathrm{NO}$ sobre o $\mathrm{Mo}^{+4}$, o oxigênio dissociado é transferido para o $\mathrm{Pd}$, onde é consumido pelo $\mathrm{CO}$ durante sua oxidação a $\mathrm{CO}_{2}$.

Inicialmente, as moléculas de $\mathrm{CO}$ são quimissorvidas sobre os átomos de Pd superficiais, e as moléculas de NO sobre os átomos de $\mathrm{Mo}^{+4}$, que são $\operatorname{logo}$ oxidados a $\mathrm{Mo}^{+6}$, desprendendo $\mathrm{N}_{2}$ como produto da reação. Neste mecanismo, as espécies $\mathrm{Pd}-\mathrm{CO}_{\text {ads }}$ têm um papel fundamental: reduzir os átomos de paládio superficiais $\left(\mathrm{Pd}^{\circ}\right)$, durante a oxidação do $\mathrm{CO}$ a $\mathrm{CO}_{2}$. Aos átomos de $\mathrm{Pd}^{\circ}$ é atribuída a função de reduzir parcialmente os átomos de $\mathrm{Mo}$, da forma $\mathrm{Mo}^{+6} \mathrm{a} \mathrm{Mo}^{+5} \mathrm{ou}$ $\mathrm{Mo}^{+4}$, preferencialmente os que estão em contato com paládio. Este mecanismo considera que o Mo, além de ser um promotor, existe como um óxido redutível na superfície do catalisador, sobre o qual o NO interagirá preferencialmente ${ }^{38-40}$.

Os autores avaliaram também o efeito do teor de Mo na adsorção de $\mathrm{NO}$ e na oxidação de propano, em ausência de $\mathrm{O}_{2}$, em catalisadores $\mathrm{Pt}-\mathrm{Mo} / \gamma-\mathrm{Al}_{2} \mathrm{O}_{3}$. As medidas de dessorção à temperatura programada (DTP) de NO indicam que o Mo é o principal responsável pela melhor seletividade à $\mathrm{N}_{2}$ nos catalisadores bimetálicos (Mo $\geq 8 \%$ ), correspondendo à Pt a função de manter as partículas de Mo em sua forma mais ativa, ou seja, parcialmente reduzida. Nos catalisadores de $\mathrm{Pd}-\mathrm{Mo} / \gamma-\mathrm{Al}_{2} \mathrm{O}_{3}$ avaliados para a redução de NO por metano, esta função é atribuída aos átomos de paládio ${ }^{41}$. Deve-se salientar que estes autores trabalharam sempre com altos teores de Mo $(>8 \%)$.

Os catalisadores $\mathrm{Pd}-\mathrm{W} / \gamma-\mathrm{Al}_{2} \mathrm{O}_{3}$ e $\mathrm{Pd}-\mathrm{Mo} / \gamma-\mathrm{Al}_{2} \mathrm{O}_{3}$, preparados a 
partir da ativação fotoquímica dos compostos organometálicos $\left[\mathrm{M}(\mathrm{CO})_{6}\right], \mathrm{M}=\mathrm{W}$ e Mo, mostraram uma atividade catalítica para decomposição de NO comparável à obtida com catalisadores preparados com sais inorgânicos desses metais. A vantagem desses catalisadores é a possibilidade de obter-se maior dispersão metálica, já que a interação desses compostos com a superfície se dá em sítios específicos (Figura 3) (sítios ácidos de Lewis $\mathrm{Al}^{+3}$ ) e se trabalha com menores conteúdos metálicos, o que previne a formação de aglomerados de óxidos voláteis desses metais, o que ocorre quando altos teores metálicos de sais inorgânicos são usados ${ }^{42-46}$.

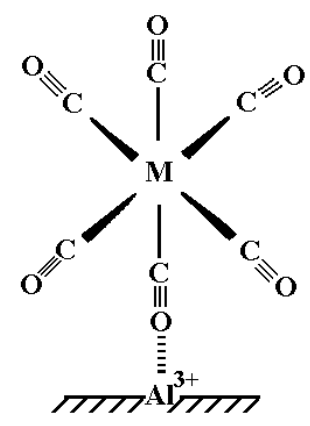

Figura 3. Interação dos compostos organometálicos $\left[M(C O)_{6}\right], M=W e$ Mo com a superfície da alumina

\section{Redução Catalítica Seletiva de NOx (RCS)}

Uma operação sob grande excesso de $\mathrm{O}_{2}$ é conhecida como queima pobre, obtendo-se quantidades de $\mathrm{NO}_{x}$ muito maiores que quando são utilizadas condições ricas. Fazendo parte deste processo estão os motores à diesel e fontes estacionárias, como caldeiras industriais ${ }^{19,47}$.

Emissões dos motores à diesel são também associadas à presença de $\mathrm{SO}_{2}$. Estas emissões são baixas nos motores à gasolina, pois a gasolina passa por um processo de hidrodessulfuração, enquanto que para o diesel, utilizado no Brasil, este processo não é realizado.

A redução catalítica seletiva de $\mathrm{NO}_{x}$, em condições de queima pobre, é um processo que permite a decomposição dos óxidos de nitrogênio, utilizando um agente redutor apropriado no fluxo de gases.

A tecnologia mais utilizada comercialmente ${ }^{47,48}$, para redução dos óxidos de nitrogênio em fontes estacionárias com excesso de oxigênio, utiliza amônia $\left(\mathrm{NH}_{3}\right)$ como agente redutor e catalisadores em forma de monolitos cerâmicos constituídos fundamentalmente por dióxido de titânio $\left(\mathrm{TiO}_{2}\right)$, trióxido de tungstênio $\left(\mathrm{WO}_{3}\right)$, pentóxido de vanádio $\left(\mathrm{V}_{2} \mathrm{O}_{5}\right)$ e trióxido de molibdênio $\left(\mathrm{MoO}_{3}\right)^{49}$.

Na presença do catalisador, a redução seletiva de NO com amônia produz nitrogênio e vapor de água ${ }^{49}$ :

$$
\begin{aligned}
& 4 \mathrm{NO}+4 \mathrm{NH}_{3}+\mathrm{O}_{2} \longrightarrow 4 \mathrm{~N}_{2}+6 \mathrm{H}_{2} \mathrm{O} \\
& 6 \mathrm{NO}+4 \mathrm{NH}_{3} \longrightarrow 5 \mathrm{~N}_{2}+6 \mathrm{H}_{2} \mathrm{O} \\
& 2 \mathrm{NO}_{2}+4 \mathrm{NH}_{3}+\mathrm{O}_{2} \longrightarrow 3 \mathrm{~N}_{2}+6 \mathrm{H}_{2} \mathrm{O} \\
& 6 \mathrm{NO}_{2}+8 \mathrm{NH}_{3} \longrightarrow 7 \mathrm{~N}_{2}+12 \mathrm{H}_{2} \mathrm{O} \\
& \mathrm{NO}+\mathrm{NO}_{2}+2 \mathrm{NH}_{3} \longrightarrow 2 \mathrm{~N}_{2}+3 \mathrm{H}_{2} \mathrm{O}
\end{aligned}
$$

Este processo deveria utilizar quantidades de amônia segundo a razão molar $\mathrm{NH}_{3} / \mathrm{NO}=1$ mas, na prática, nessas condições não é obtida uma mistura homogênea do agente redutor com os óxidos de nitrogênio. Desta forma, é necessário utilizar quantidades maiores de amônia. Isto gera um excesso de amônia que é descarregado na atmosfera contaminando o meio ambiente. Também o excesso de
$\mathrm{NH}_{3}$ pode gerar sulfato de amônio $\left[\left(\mathrm{NH}_{4}\right)_{2} \mathrm{SO}_{4}\right]$ e bissulfato de amônio $\left(\mathrm{NH}_{4} \mathrm{HSO}_{4}\right)$ na presença de $\mathrm{SO}_{3}$ e vapor de água. Isto causa um aumento do material particulado no fluxo de gás, assim como a deposição na superfície do catalisador e no equipamento, ocasionando sérios problemas operacionais. Estes inconvenientes mostram que o controle das emissões de $\mathrm{NO}_{x}$ é um problema não resolvido, que faz com que muitos especialistas da área, no mundo inteiro, continuem trabalhando na busca de outros agentes redutores.

Os compostos mais estudados são os parcialmente oxigenados, como álcoois e cetonas ${ }^{50-52}$ e os não-oxigenados como hidrocarbonetos olefínicos e parafínicos ${ }^{53-58}$, em especial o propeno $\left(\mathrm{C}_{3} \mathrm{H}_{6}\right)$. Os catalisadores geralmente utilizam alumina e zeólitas como suporte de metais e/ou óxidos de metais de transição. A reação simplificada é a seguinte ${ }^{59}$ :

$2 \mathrm{NO}+\mathrm{C}_{\mathrm{x}} \mathrm{H}_{\mathrm{y}}+(4 \mathrm{x}+\mathrm{y}-4) / 4 \mathrm{O}_{2} \longrightarrow \mathrm{N}_{2}+\mathrm{xCO}_{2}+\mathrm{y} / 2 \mathrm{H}_{2} \mathrm{O}$

Iwamoto e colaboradores ${ }^{60,61}$ foram os primeiros a constatar que as zeólitas trocadas com íons cobre eram ativas para a decomposição de NO e, em particular, o catalisador Cu-ZSM-5 mostrou uma elevada atividade quando comparado com os catalisadores tradicionais. Este catalisador, apesar de ter sua atividade reduzida na presença de oxigênio e dióxido de enxofre, é até hoje estudado como uma alternativa interessante na decomposição de $\mathrm{NO}^{62,63}$. Esses pesquisadores ${ }^{60,61}$ estudaram zeólitas trocadas ionicamente com $\mathrm{H}^{+}, \mathrm{Na}^{+}, \mathrm{K}^{+}$, $\mathrm{Mg}^{2+}, \mathrm{Ca}^{2+}, \mathrm{Cr}^{3+}, \mathrm{Fe}^{3+}, \mathrm{Co}^{3+}, \mathrm{Ni}^{2+}, \mathrm{Cu}^{2+}, \mathrm{Zn}^{2+}$ e $\mathrm{Ag}^{+}$e observaram o aumento na atividade desses catalisadores quando um agente redutor era utilizado. Os autores classificaram os agentes redutores em seletivos $\left(\mathrm{C}_{2} \mathrm{H}_{4}, \mathrm{C}_{3} \mathrm{H}_{6}, \mathrm{C}_{4} \mathrm{H}_{8}, \mathrm{C}_{3} \mathrm{H}_{8}\right.$, álcool $)$ e não seletivos $\left(\mathrm{H}_{2}, \mathrm{CO}\right.$, $\mathrm{CH}_{4}$ ). Os resultados para propeno e $\mathrm{CO}$ são mostrados na Figura 4.

$\mathrm{Na}$ Figura $4 \mathrm{a}$ observa-se que a introdução de oxigênio na mistura $\mathrm{C}_{3} \mathrm{H}_{6}+\mathrm{NO}$ resultou em um aumento da atividade catalítica para a redução de NO, nas temperaturas entre 473-673 K. Neste caso, notou-se que a presença de oxigênio era essencial para a reação. Já para os redutores não seletivos (Figura $4 b$ ) este efeito foi totalmente diferente; para a mistura $\mathrm{CO}+\mathrm{NO}$ observou-se alta conversão de $\mathrm{NO}$ a $573 \mathrm{~K}$ entretanto, quando o oxigênio foi introduzido no sistema de reação, a conversão de NO diminui quase totalmente no intervalo de temperatura estudado. Deste estudo conclui-se que o CO não é um redutor efetivo na presença de oxigênio. Entretanto, o catalisador Cu-ZSM-5 é vulnerável à desativação na presença de vapor de água e $\mathrm{SO}_{2}$, assim como apresenta baixa estabilidade térmica ${ }^{64}$. Foi observado que $\mathrm{OSO}_{2}$ causa um efeito reversível sobre a atividade inicial do catalisador $\mathrm{Cu}-\mathrm{ZSM}-5$, para a redução de $\mathrm{NO}$ por hidrocarbonetos tais como etileno, propano e propeno, mas após um longo período de exposição a este gás, a desativação do catalisador é permanente. Este fato foi atribuído à adsorção do gás sobre os cátions cobre. A água também inibe a atividade catalítica, dependendo da quantidade utilizada e da temperatura. Este efeito é causado provavelmente pela adsorção competitiva da água sobre o metal. Também foi demostrado, no mesmo trabalho, que na presença de água e altas temperaturas ocorre a desaluminação da estrutura da zeólita. Isto é traduzido como uma perda da atividade catalítica dos íons cobre que se encontram nos sítios de troca iônica gerados pelos sítios de alumínio na zeólita.

O estudo do mecanismo da RCS de NO com propano na presença de excesso de oxigênio revelou que a primeira etapa da reação é a oxidação de $\mathrm{Cu}^{+} \mathrm{a} \mathrm{Cu}^{2+}$ e que a formação de $\mathrm{NO}_{2}$ é facilitada pelo íon $\mathrm{Cu}^{2+}$. $\mathrm{O} \mathrm{NO}$ formado reage com propano formando um composto nitrito-propano que, por sua vez, se decompõe a uma temperatura inferior que a requerida para a decomposição de $\mathrm{NO}^{65}$.

Outros autores também têm estudado diferentes tipos de zeólitas substituídas com cobalto, ferro e gálio ${ }^{48,66}$. Em geral, a atividade catalítica depende do tipo de zeólita. O catalisador Co-ZSM-5 tam- 

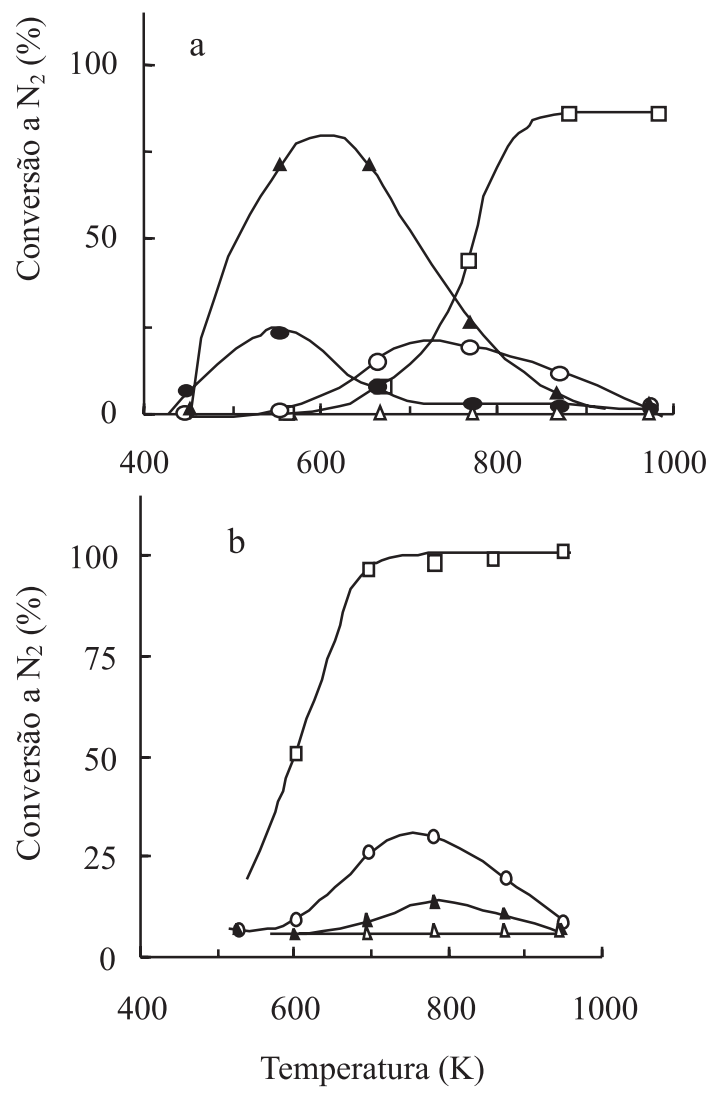

Figura 4. Dependência da atividade catalítica do catalisador Cu-ZSM-5 com a temperatura, para decompor o NO utilizando diferentes condições de reação. a: $(\bigcirc) \mathrm{NO}(1000 \mathrm{ppm}) ;(\triangle) \mathrm{NO}(1000 \mathrm{ppm})+\mathrm{O}_{2}(1 \%) ;(\square) \mathrm{NO}$ $(1000 \mathrm{ppm})+\mathrm{C}_{3} \mathrm{H}_{6}(166 \mathrm{ppm}) ;(\mathbf{O}) \mathrm{NO}(1000 \mathrm{ppm})+\mathrm{O}_{2}(1 \%)+\mathrm{C}_{3} \mathrm{H}_{6}(166$ ppm); ( $\mathbf{\Delta}) \mathrm{NO}(1000 \mathrm{ppm})+\mathrm{O}_{2}(1 \%)+\mathrm{C}_{3} \mathrm{H}_{6}(1000 \mathrm{ppm}) \cdot \mathrm{b}:(\mathrm{O}) \mathrm{NO}(1000$ ppm); $(\triangle) \mathrm{NO}(1000 \mathrm{ppm})+\mathrm{O}_{2}(1 \%) ;(\square) \mathrm{NO}(1000 \mathrm{ppm})+\mathrm{CO}(1000$ ppm); ( $\mathbf{\Delta}) \mathrm{NO}(1000 \mathrm{ppm})+\mathrm{O}_{2}(1 \%)+\mathrm{CO}(1000 \mathrm{ppm})$. Reproduzida da ref. 61 com permissão da Elsevier

bém desativa na presença de vapor de água e $\mathrm{SO}_{2}$, devido à adsorção preferencial do $\mathrm{SO}_{2}$ sobre os sítios de cobalto ${ }^{48}$.

Os catalisadores de metal de transição/alumina mostram atividades comparáveis com as dos catalisadores sobre zeólitas para a RCS com propeno. Análises de DRX mostraram a formação da fase aluminato para catalisadores $\mathrm{Cu}, \mathrm{Ni}$ e $\mathrm{Co} / \mathrm{Al}_{2} \mathrm{O}_{3}$. Neste estudo foi confirmada a formação da fase espinela, o que demostra que os cátions destes metais de transição são incorporados ao suporte. A formação de uma fase aluminato permite a dispersão da fase ativa na superfície do suporte e é responsável pela alta atividade obtida na reação de RCS de NO com propeno, para estes catalisadores ${ }^{56}$.

Para o catalisador $\mathrm{Co} / \mathrm{Al}_{2} \mathrm{O}_{3}$ foi sugerido que o papel do promotor é oxidar $\mathrm{NO}$ com oxigênio para formar $\mathrm{NO}_{2}$ que, subseqüentemente, reagirá com o alqueno sobre a alumina produzindo nitrogênio. Também foi comprovado que altos conteúdos de cobalto promovem a oxidação do propeno em detrimento da conversão de $\mathrm{NO}^{67}$.

Catalisadores suportados com ouro são também ativos para a redução de $\mathrm{NO}$ com propeno ${ }^{68}$. $\mathrm{O}$ catalisador $\mathrm{Au} / \mathrm{Al}_{2} \mathrm{O}_{3}$ mostrou a maior atividade para os catalisadores de ouro testados na temperatura de $673 \mathrm{~K}$. A temperaturas menores, o catalisador $\mathrm{Au} / \mathrm{ZnO}$ apresentou a maior conversão a nitrogênio.

Catalisadores de metais do grupo da platina apresentam boa atividade a baixas temperaturas, são termicamente estáveis e não desativam na presença de $\mathrm{SO}_{2}$. Obuchi e colaboradores ${ }^{69}$ estudaram a reação de RCS na presença de propeno para os catalisadores de Pt, Ir, Pd, Rh e Ru suportados sobre $\gamma$-alumina. Os catalisadores de Pt, $\mathrm{Rh}$ e $\mathrm{Ru}$ apresentaram maior atividade, observando-se conversões de NO acima de $50 \%$. No caso do Rh, mais de $90 \%$ do NO consumido foi transformado em nitrogênio. Já para a Pt foi formado principalmente $\mathrm{N}_{2} \mathrm{O}$. Somente $1 / 3$ do $\mathrm{NO}$ foi transformado em nitrogênio.

Esses autores compararam estes catalisadores com o catalisador $\mathrm{Cu}-\mathrm{ZSM}-5$, quando expostos aos gases de escape de um motor diesel operando com óleo diesel comercial que contém $\mathrm{SO}_{2}$, durante $5 \mathrm{~h}$ de reação. Dessa forma, foi concluído que os catalisadores de metais do grupo da platina mantiveram a atividade em níveis constantes, ao contrário do catalisador Cu-ZSM-5 que, após 4 h 30 min, teve uma diminuição da metade da conversão de NO. Isto demonstra que a eficiência dos catalisadores de metais do grupo da platina, suportados em $\gamma$-alumina, é maior que a do catalisador Cu-ZSM-5 para operar na presença de $\mathrm{SO}_{2}$. Catalisadores $\mathrm{CuO} / \mathrm{TiO}_{2}$ e $\mathrm{Pt} / \mathrm{TiO}_{2}$ mostraram também baixa seletividade ${ }^{70}$.

Burch e colaboradores ${ }^{71}$ estudaram o possível mecanismo que acontece sobre catalisadores de platina, na reação de RCS com hidrocarbonetos. Nesse trabalho foi proposto que o mecanismo contém duas etapas: redução dos sítios de platina pelo hidrocarboneto e decomposição do NO, para gerar oxigênio e nitrogênio, sobre os sítios de platina reduzida. Este mecanismo também prevê que os catalisadores de platina serão ativos em temperatura inferiores a $350{ }^{\circ} \mathrm{C}$.

Em estudo posterior, Burch e colaboradores ${ }^{72}$ estudaram o efeito de diferentes agentes redutores sobre catalisadores de platina, constatando que o tolueno permite eliminar o problema da formação de $\mathrm{N}_{2} \mathrm{O}$ através da inibição da adsorção de NO molecular, facilitando sua dissociação. Numerosos esforços têm sido realizados para melhorar a atividade e seletividade desses catalisadores. A adição de promotores, tais como metais alcalinos e alcalino-terrosos ( $\mathrm{Na}, \mathrm{K}$, $\mathrm{Cs}, \mathrm{Mg}, \mathrm{Ca}, \mathrm{Sr}$ e Ba), a catalisadores de platina suportados, em geral, não proporcionou grandes benefícios ${ }^{57,72,73}$.

Denton e colaboradores ${ }^{74}$ realizaram experimentos com o catalisador $\mathrm{Pt} / \mathrm{SiO}_{2}$. Este estudo propôs um mecanismo tipo redox, onde, em condições de excesso de oxigênio, o propeno protege, do oxigênio, os sítios ativos de $\mathrm{Pt}^{0}$, permitindo a adsorção do NO para formar $\mathrm{N}_{2}$ e $\mathrm{N}_{2} \mathrm{O}$. Por outro lado, o oxigênio impede o bloqueio dos sítios ativos com material carbonoso originado da decomposição do propeno.

A influência da estrutura do hidrocarboneto nesta reação foi estudada para o catalisador $\mathrm{Cu} / \mathrm{Al}_{2} \mathrm{O}_{3}{ }^{75}$. Foi observado aumento da velocidade de reação com o aumento do número de carbonos em alcanos lineares e a velocidade para a redução catalítica seletiva de NO foi menor para hidrocarbonetos ramificados, que para os lineares com o mesmo número de átomos de carbono. Os autores também consideraram a energia média de ligação como um parâmetro útil para estimar a capacidade do hidrocarboneto de reduzir NO, na reação de redução catalítica seletiva de NO com hidrocarbonetos.

Outros sistemas catalíticos estudados na RCS de NO utilizam óxido de cério como promotor. $\mathrm{O}$ uso do cério é normalmente relacionado com a sua capacidade de armazenar oxigênio e com a propriedade de estabilização do suporte alumina ${ }^{76,77}$. Na presença de um metal de transição, o óxido de cério favorece a formação de espécies oxidadas.

A alumina $\left(\mathrm{Al}_{2} \mathrm{O}_{3}\right)$ também tem sido testada para a decomposição de $\mathrm{NO}$ com hidrocarbonetos ${ }^{53,78}$, sendo ativa e seletiva para a formação de nitrogênio a temperaturas acima de $400{ }^{\circ} \mathrm{C}$, nas condições experimentais utilizadas neste estudo. Obteve-se também formação de $\mathrm{N}_{2} \mathrm{O}$ e $\mathrm{NO}_{2}$ sobre a alumina, depois de ter sido atingida a oxidação completa do propeno, em temperaturas acima de $565{ }^{\circ} \mathrm{C}$.

Catalisadores de $\mathrm{In}_{2} \mathrm{O}_{3} / \mathrm{Al}_{2} \mathrm{O}_{3}$ mostraram elevada atividade, utilizando propeno como agente redutor na presença de $9 \%$ de oxigênio 
e $7 \%$ de água na velocidade espacial de $30000 \mathrm{~h}^{-1}$. Os autores identificaram a existência de um mecanismo bifuncional, onde espécies de óxido de índio oxidam parcialmente o propeno em acroleína e acetaldeído e, posteriormente, a alumina utiliza estes hidrocarbonetos oxigenados para reduzir $\mathrm{NO}_{x}$ a $\mathrm{N}_{2}{ }^{77}$.

Nos últimos anos tem-se dado atenção especial aos catalisadores de prata suportados em alumina. Miyadera e colaboradores ${ }^{80,81}$ foram os primeiros a relatar a potencialidade dos catalisadores de $\mathrm{Ag}$ / $\gamma-\mathrm{Al}_{2} \mathrm{O}_{3}$ na RCS de NOx com hidrocarbonetos. Estes resultados têm sido também obtidos por outros pesquisadores ${ }^{78,82}$. A boa atuação dos catalisadores de prata é refletida no seu comportamento em relação a catalisadores de outros metais de transição.

Na Tabela 2 são mostrados os resultados obtidos para diferentes catalisadores, quando se adiciona $10 \%$ de água na mistura reacional. Como é observado, o catalisador de prata mostrou alta atividade, com a presença ou não de água na mistura reacional em temperaturas $\geq 450{ }^{\circ} \mathrm{C}$. Em estudo da reação por $100 \mathrm{~h}$, na presença de $10 \%$ de vapor de água, o catalisador continuou mostrando elevada atividade. Isto deve-se à fraca adsorção da água na superfície da prata ${ }^{80}$. Adicionalmente, Iglesias-Juez e colaboradores ${ }^{83}$ obtiveram para o catalisador $\mathrm{Ag} / \mathrm{Al}_{2} \mathrm{O}_{3}$, com $1,5 \%$ e $4,5 \%$ de prata, em torno de $90 \%$ de conversão numa faixa de temperatura de $480-550{ }^{\circ} \mathrm{C}$, usando $3 \%$ de vapor de água na composição reacional. Catalisadores de prata também mostraram elevada atividade para a redução de NO na presença de $\mathrm{SO}_{2}$.

Outros agentes redutores, compostos orgânicos com oxigênio na estrutura, foram testados para a reação de RCS com o catalisador de prata/alumina. O etanol, a acetona e o 2-propanol foram efetivos para a redução do NO no intervalo de temperaturas entre 250$400{ }^{\circ} \mathrm{C}^{80,84}$.

Catalisadores de prata suportada em zeólitas, principalmente ZSM-5, têm sido estudados por Furusawa e colaboradores ${ }^{85}$. Os autores obtiveram seletividades a nitrogênio de $100 \%$, para $24 \mathrm{~h}$ de reação. A conversão obtida neste caso foi de apenas $10 \%$.

\section{Fatores que afetam a conversão de NO para a RCS de $N_{x}$}

A eficiência dos catalisadores estudados para a decomposição catalítica seletiva de $\mathrm{NO}_{\mathrm{x}}$ depende de vários fatores, como o conteúdo de metal, tipo de pré-tratamento, concentração e tipo de agente redutor, concentração de oxigênio, temperatura de reação e velocidade espacial. Esses fatores serão analisados a seguir, tomando como exemplo catalisadores que utilizam prata como metal ativo.
Maiores conversões de NO a nitrogênio são obtidas com teores de prata de aproximadamente $2 \%$ em massa. Aumento na quantidade de metal reduz drasticamente as conversões de NO. Nas condições da reação de RCS de $\mathrm{NO}_{x}$ com hidrocarbonetos, partículas de prata metálica prevalecem para teores de prata acima de $6 \%$ em massa, enquanto espécies $\mathrm{Ag}^{+}$são majoritárias com aproximadamente $2 \%$ em massa. Neste último caso, a estabilização de um estado oxidado pode ser explicada pela maior dispersão, assim como maior interação com a alumina ${ }^{86,87}$.

Outros estudos têm mostrado a importância do pré-tratamento dos catalisadores de prata ${ }^{51}$. Resultados mostram que, com o catalisador Ag/alumina previamente reduzido, foi obtido apenas $50 \%$ de conversão de NO, enquanto que com o catalisador previamente oxidado a conversão foi de $80 \%$. Este resultado foi obtido utilizando propeno, e também etanol, como agente redutor. Além disso, a seletividade também foi maior para o catalisador previamente oxidado. As partículas de $\mathrm{Ag}^{0}$, tendo elétrons disponíveis, promovem a oxidação do propeno em detrimento da redução do $\mathrm{NO}^{86}$. Como conseqüência, a calcinação do catalisador $\mathrm{Ag} / \mathrm{Al}_{2} \mathrm{O}_{3}$ em uma atmosfera oxidante favorece a reação de RCS de NO com hidrocabonetos.

Outro parâmetro muito estudado tem sido a concentração do agente redutor. Um dos estudos da conversão de NO para diferentes concentrações de propeno mostrou que a conversão de NO aumentava até uma relação $\mathrm{NO}: \mathrm{C}_{3} \mathrm{H}_{6}$ de 1:1. Já para uma relação $1: 2$ a conversão de NO diminui ${ }^{79}$. Este resultado é semelhante ao obtido para o catalisador $0,17 \% \mathrm{Au} / \mathrm{Al}_{2} \mathrm{O}_{3}$ para o qual uma vez atingida a condição 1:1 obteve-se uma conversão constante. Dessa forma, a relação $1: 1$ foi escolhida como a mais adequada aos estudos ${ }^{68}$.

Outro estudo ${ }^{54}$ mostrou um aumento da conversão de NO, inclusive para relações maiores de 1:1. Observou-se também que o intervalo de temperaturas no qual o catalisador é ativo para a conversão de NO aumenta com a concentração do redutor.

A concentração de oxigênio na mistura reacional têm sido amplamente estudada ${ }^{54,68}$. Em geral, quantidades acima de $2 \%$ do fluxo total oferecem boas conversões de NO.

A temperatura de reação é outro parâmetro importante, já que dela depende a existência ou não das espécies ativas. Os catalisadores de Ag são geralmente utilizados em temperaturas entre $350-500{ }^{\circ} \mathrm{C}$, uma vez que neste intervalo é observada a maior atividade para a redução dos $\mathrm{NO}_{\mathrm{x}}$ sem mudança significativa na textura do catalisador.

A velocidade espacial (vazão total/volume do reator), na qual é realizada a reação de redução de NO, é também um fator muito impor-

Tabela 2. Redução catalítica seletiva de $\mathrm{NO}$ com propeno para diferentes catalisadores suportados em alumina; $\left(500 \mathrm{ppm} \mathrm{NO}+500\right.$ ppm $\mathrm{C}_{3} \mathrm{H}_{6}$ $+10 \% \mathrm{O}_{2} / \mathrm{N}_{2}+0 \%$ ou $\left.10 \% \mathrm{H}_{2} \mathrm{O}\right) ; 6400 \mathrm{~h}^{-1}$. Reproduzida da ref. $80 \mathrm{com}$ autorização da Elsevier

\begin{tabular}{|c|c|c|c|c|c|c|c|}
\hline \multirow[t]{2}{*}{ Catalisador* } & \multirow[t]{2}{*}{$\mathrm{H}_{2} \mathrm{O}(\%)$} & \multicolumn{6}{|c|}{ Conversão de $\mathrm{NO}_{\mathrm{x}}(\%)$} \\
\hline & & $300{ }^{\circ} \mathrm{C}$ & $350{ }^{\circ} \mathrm{C}$ & $400{ }^{\circ} \mathrm{C}$ & $450{ }^{\circ} \mathrm{C}$ & $500{ }^{\circ} \mathrm{C}$ & $550^{\circ} \mathrm{C}$ \\
\hline \multirow[t]{2}{*}{$\mathrm{Al}_{2} \mathrm{O}_{3}$} & 0 & 11,6 & 20,3 & 41,7 & 71,2 & 79,1 & 44,7 \\
\hline & 10 & 2,1 & 3,4 & 4,3 & 9,1 & 23,8 & 31,0 \\
\hline \multirow[t]{2}{*}{$\mathrm{Co} / \mathrm{Al}_{2} \mathrm{O}_{3}$} & 0 & 13,4 & 75,7 & 75,8 & 60,1 & 43,3 & 14,5 \\
\hline & 10 & 2,9 & 5,3 & 19,9 & 41,6 & 44,4 & 21,7 \\
\hline \multirow{2}{*}{$\mathrm{Ag} / \mathrm{Al}_{2} \mathrm{O}_{3}$} & $\mathbf{0}$ & 9,0 & 52,8 & 80,5 & 76,6 & 62,4 & 24,5 \\
\hline & 10 & 0,8 & 10,5 & 40,0 & 70,9 & 62,3 & 26,6 \\
\hline \multirow[t]{2}{*}{$\mathrm{Cu} / \mathrm{Al}_{2} \mathrm{O}_{3}$} & 0 & 34,8 & 35,7 & 31,2 & 23,4 & 14,3 & 7,0 \\
\hline & 10 & 3,0 & 12,2 & 12,8 & 9,7 & 4,4 & 4,7 \\
\hline \multirow[t]{2}{*}{$\mathrm{V} / \mathrm{Al}_{2} \mathrm{O}_{3}$} & 0 & 3,1 & 5,8 & 9,9 & 11,1 & 7,3 & 7,5 \\
\hline & 10 & 1,1 & 1,2 & 1,8 & 2,4 & 2,6 & 6,1 \\
\hline \multirow[t]{2}{*}{$\mathrm{Cr} / \mathrm{Al}_{2} \mathrm{O}_{3}$} & 0 & 10,4 & 9,5 & 8,8 & 7,6 & 5,0 & 4,2 \\
\hline & 10 & 4,5 & 4,7 & 3,7 & 2,8 & 2,2 & 3,0 \\
\hline
\end{tabular}

${ }^{*}$ teor de metal $=2 \%$ 
tante. Em estudo realizado para um catalisador $1,2 \% \mathrm{Ag} / \gamma-\mathrm{Al}_{2} \mathrm{O}_{3}$ utilizando diferentes velocidades espaciais, observou-se que as conversões de propeno e de $\mathrm{NO}$ a nitrogênio aumentaram com a diminuição de velocidade espacial, e o máximo de conversão deslocou-se para temperaturas menores ${ }^{89}$. Enquanto que para $25000 \mathrm{~h}^{-1}$ foi obtida uma conversão de NO a nitrogênio próxima de $100 \%$, para $250000 \mathrm{~h}^{-1}$ esta foi apenas de $45 \%$. Observou-se também que à menor temperatura corresponde a menor velocidade espacial, para a qual $90 \%$ do NO foi convertido em nitrogênio e a conversão correspondente de propeno foi também de $90 \%$. Isto é, para cada molécula de propeno consumida, uma molécula de NO foi reduzida a nitrogênio.

De maneira geral, a menores temperaturas e menores velocidades espaciais o processo é mais eficiente. Isto provavelmente está relacionado com o fato de que a reação de redução catalítica seletiva compete com a oxidação total do agente redutor e esta última é usualmente favorecida a temperaturas mais elevadas ${ }^{89}$. Velocidades espaciais de $25000 \mathrm{~h}^{-1}$ ou menores podem ser uma dificuldade tecnológica no tratamento dos gases de exaustão para fontes móveis. Dessa forma, a utilização de catalisadores de $\mathrm{Ag} / \gamma-\mathrm{Al}_{2} \mathrm{O}_{3}$ em condições de baixa velocidade espacial é aplicável em fontes estacionárias.

Dos aspectos anteriormente analisados pode-se concluir que a RCS de $\mathrm{NO}_{\mathrm{x}}$ com propeno envolve um mecanismo complexo que depende de muitos fatores. A Figura 5 mostra uma proposta de mecanismo de reação para a redução catalítica seletiva de $\mathrm{NO}_{x}$ por propeno, utilizando catalisadores de $\mathrm{Ag} / \mathrm{Al}_{2} \mathrm{O}_{3}{ }^{90}$.

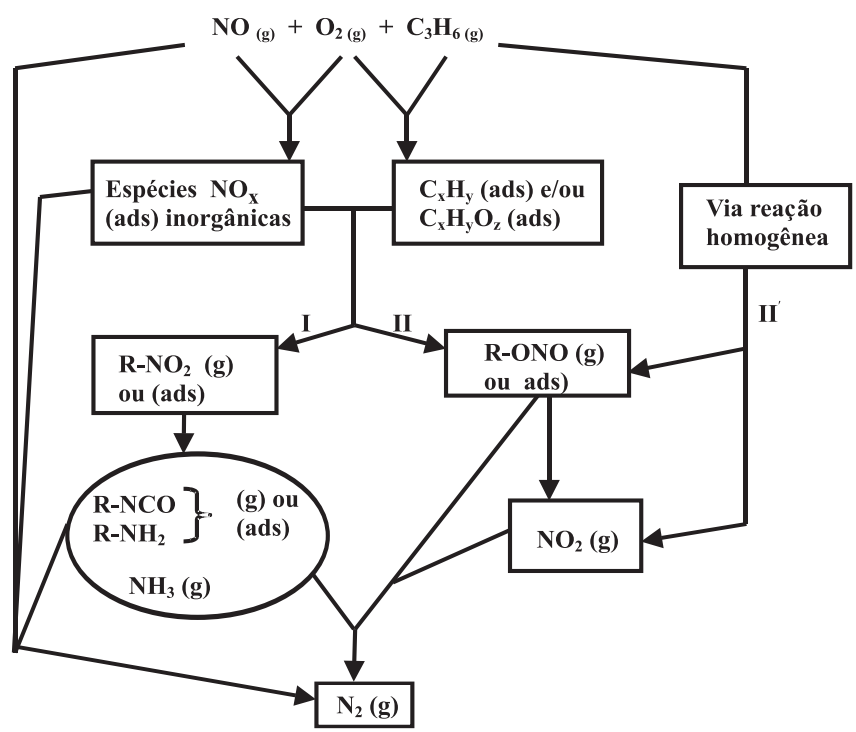

Figura 5. Reação simplificada da redução catalítica seletiva de $\mathrm{NO}_{x}$ com propeno para o catalisador $\mathrm{Ag} / \mathrm{Al}_{2} \mathrm{O}_{3}$. Reproduzida da ref. 90 com permissão da Elsevier

O oxigênio pode reagir com o NO e com o propeno para formar espécies $\mathrm{NO}_{\mathrm{x}}(\mathrm{x}>1)$ adsorvidas na superfície do catalisador, assim como hidrocarbonetos parcialmente oxidados ${ }^{91}$. Uma das funções da prata seria favorecer esse processo de oxidação ${ }^{53}$.

Posteriormente, estas espécies formadas reagem segundo duas rotas. Primeiramente (rota I) formam-se compostos orgânicos nitrogenados do tipo $\mathrm{R}-\mathrm{NO}_{2}$ que, subseqüentemente, reagem e se decompõem sobre o catalisador para formar isocianatos, grupos amino e, finalmente, amônia ${ }^{91-94}$. Seguindo a rota II, seriam formados compostos orgânicos nitrogenados do tipo $\mathrm{R}-\mathrm{NO}_{2}$ que, subseqüentemente, são oxidados a $\mathrm{NO}_{2}$. Também pode ocorrer a formação de $\mathrm{NO}_{2}$ via reação homogênea (rota II') ${ }^{95}$. Eventualmente, espécies reduzidas formadas na rota $\mathrm{I}\left(-\mathrm{NCO}, \mathrm{R}-\mathrm{NH}_{2}, \mathrm{NH}_{3}\right.$ ) podem reagir com espécies oxidadas (organonitrito ou $\mathrm{NO}_{2}$ ) para formar $\mathrm{N}_{2}{ }^{96}$. As formas reduzidas podem também reagir diretamente com $\mathrm{NO}$ ou com espécies inorgânicas $\mathrm{NO}_{\mathrm{x}}$ adsorvidas para formar $\mathrm{N}_{2}{ }^{97}$.

\section{CONSIDERAÇÕES FINAIS}

Os óxidos de nitrogênio são importantes contaminantes ambientais que podem causar graves danos à saúde do homem e à natureza em geral. Estes óxidos podem ser decompostos cataliticamente utilizando catalisadores de três vias para motores de gasolina convencionais e mediante o processo de redução catalítica seletiva, no caso dos motores à diesel e à combustão em caldeiras e fornos.

Estes dois processos têm seus inconvenientes, por exemplo, o primeiro utiliza metais como ródio que, além de seu elevado custo, apresenta uma incompatibilidade das reservas mundiais com a demanda requerida. $\mathrm{O}$ segundo, no processo comercial conhecido, utiliza amônia como agente redutor, cujo excesso é descarregado diretamente na atmosfera.

Estes inconvenientes levaram a um aumento considerável da pesquisa de novos sistemas catalíticos contribuindo, assim, para o desenvolvimento da química do estado sólido e o conhecimento do funcionamento desses catalisadores.

\section{AGRADECIMENTOS}

Agradecemos à FAPERGS, CNPq e COPESUL pelo suporte financeiro.

\section{REFERÊNCIAS}

1. Alloway B. J.; Ayres D. C.; Chemical Principles of Environmental Pollution, Blackie Academic \& Professional: London, 1994.

2. Atkinson, R.; Atmos. Environ. 2000, 34, 2063.

3. Moulijn, J. A.; van Leeuwen, P. W. N. M.; van Santen, R. A.; Catalysis. An integrated approach to homogeneous, heterogeneous and industrial catalysis, Elsevier Science: Netherlands, 1993.

4. Reeve, R. N.; Environmental Analysis, John Wiley \& Sons: Chichester, 1999.

5. Environmental Protection Agency (EPA), Office of Communications, Education and Public Affairs Editorial Services Division, Abril, 1994.

6. Pimentel, A. S.; Arbilla, G.; Quim. Nova 1997, 20, 252.

7. Relatório do Laboratório de Emissões Veiculares (LEV) do CENPES PETROBRAS, 1995.

8. Leone, J. A.; Seinfeld, J. H.; Atmos. Environ. 1988, 19, 437.

9. Tolentino, M.; Rocha Filho, R. C.; Silva, R. R.; O Azul do Planeta: um retrato da atmosfera, Ed. Moderna: São Paulo, 1995.

10. Borges, S. S. S.; Gomes, M. G.; Anais Assoc. Bras. Quim. 1997, 46, 242.

11. Armor, J. N.; Appl. Catal., B 1992, 1, 221.

12. Egues, S.; Peterson, M.; José, H. J.; Kuhnen, N. C.; Anais Assoc. Bras. Quim. 1997, 46, 142.

13. Harrison, B.; Wyatt, M.; Gough, G.; Royal Society of Chemical 1982, 5 , 127.

14. Harrison, R. M.; Pollution: Causes, effects, and control, $2^{\text {th }}$ ed., The Royal Society of Chemistry: Cambridge, 1995.

15. Nakata, Y.; Goto, T.; Niimi, Y.; Motita, S.; J. Clin. Anesth. 1999, 11, 477.

16. Isuyama, R.; Ciência Hoje 2000, 28, 78.

17. Lopes, C. V. M.; Krüger, V.; Propostas para o ensino da química: Poluição do ar e lixo, SE/CECIRS: Porto Alegre, 1997.

18. Stanley E.; Environmental Chemistry, $7^{\text {th }}$ ed., Lewis Publishers: Boca Raton, 2000.

19. Seinfeld, J. H.; Atmospheric Chemistry and Physics of Air Pollution, Wiley: New York, 1986.

20. Makalady, L. Em Perspectives in Environmental Chemistry; Macalady, D., ed.; Oxford University, 1998.

21. Harrison, R. M.; de Mora, S. J.; Introductory Chemistry for the Environmental Sciences, $2^{\text {th }}$ d., Cambridge University Press: New York, 1996.

22. http://www.race.nuca.ie.ufrj.br/eco/trabalhos/comu2/1.doc, acessada em Maio 2003. 
23. http://www.saebrasil.org.br/eventos/congresso2002/papers2002/emp_nhtm\#emp_n-q.htm, acessada em Maio 2003.

24. Fritz, A.; Pitchon, V.; Appl. Catal., B 1997, 13, 1.

25. Stern, A. C.; Air pollution, their transformation and transport, Academic Press: New York, 1976, vol. I.

26. Muraki, H.; Shinjoh, H.; Fujitani, Y.; Ind. Eng. Chem. Prod. Res. Dev. 1986, $25,419$.

27. Shelef, M.; Graham, G. W.; Catal. Rev. Sci. Eng. 1994, 36 , 433.

28. Bramwenda, G. R.; Ogata, A.; Obuchi, A.; Oi, J.; Mizuno, K.; Skrzypek, J.; Appl. Catal., B 1995, 6, 311.

29. Taylor, K. C.; Catal. Rev. Sci. Eng. 1993, 35, 457.

30. Summers, J. C.; Monroe, D. R.; Ind. Eng. Chem. Prod. Res. Dev. 1981, $20,23$.

31. Summers, J. C.; Williamson, W.; Henk, M.; SAE Paper 880281, 1989.

32. Adams, K. M.; Gandhi, H. S.; Ind. Eng. Chem. Prod. Res. Dev. 1983, 22, 207.

33. Gandhi, H. S.; Yao, H. C.; Stepien, H. K.; Catalysis under Transient Conditions, ACS Symp. Ser. No 178, Bell and Hegedus Eds., Am. Chem. Soc., 1982, p. 143.

34. Halasz, I.; Brenner, A.; Shelef, M.; Catal. Lett. 1992, 16, 311.

35. Halasz, I.; Brenner, A.; Shelef, M.; Catal. Lett. 1993, 18, 289.

36. Halasz, I.; Brenner, A.; Shelef, M.; Appl. Catal., B 1993, 2,131.

37. Schmal, M.; Baldanza, M. A. S.; Noronha, F. B.; J. Catal. 1999, 188, 270.

38. Schmal, M.; da Silva, M. A. P.; Machado, B. J. F.; Simpósio Íberoamericano de Catálise, Rio de Janeiro, Brasil, 2000.

39. Schmal, M.; Baldanza, M. A. S.; Vannice, M. A.; J. Catal. 1999, 185, 138.

40. Schmal, M.; da Silva, M. A. P.; Vieira, R. A. M.; Appl. Catal., A 2000, 190, 177.

41. Schmal, M.; de Mello, L.; Baldanza, M. A. S.; Noronha, F. B.; Proceedings of the 12 $2^{\text {th }}$ International Congress of Catalysis, Granada, Spain, 2000.

42. Baibich, I. M.; dos Santos, J. H.; Stedile, F.; Santarosa, V. E.; Baumvol, I.; Polyhedron 1997, 16, 1937.

43. Baibich, I. M.; dos Santos, J. H.; da Silveira, V. C.; Gigola, C. E.; Sica, A. M.; Can. J. Anal. Sci. Spectrosc. 1998, 43, 26.

44. Sica, A. M.; dos Santos, J. H.; Baibich, I. M.; Gigola, C. E.; J. Mol. Catal. A: Chem. 1999, 137, 287.

45. Sica, A. M.; Baibich, I. M.; Gigola, C. E.; J. Mol. Catal. A: Chem. 2003, $195,225$.

46. de Almeida, R. M. J.; Pergher, S. B. C.; Gigola, C. E.; Baibich, I. M.; Can. J. Anal. Sci. Spectrosc. 2003, 48, 21.

47. Chafik, T.; Kameoka, S.; Ukisu, Y.; Miyadera, T.; J. Mol. Catal. A: Chem. 1998, 136, 203.

48. Li, Y.; Armor, J. N.; Appl. Catal., B 1992, 1, 221.

49. Nalven, G. F.; The Environment: Air, Water, and Soil, American Institute of Chemical Engineers, Alche: New York, 1997.

50. Masuda, M.; Tsujimura, K.; Shinoda, K.; Kato, T.; Appl. Catal., B 1996, 8,33 .

51. Aoyama, N.; Yoshida, K.; Abe, A.; Miyadera, T.; Catal. Lett. 1997, 43, 249.

52. Takagi, K.; Kobajashi, T.; Ohkita, H.; Mizushima, T.; Kakuta, N.; Abe, A.; Yoshida, K.; Catal. Today 1998, 45, 123.

53. Meunier, F. C.; Breen, J. P.; Zuzaniuk, V.; Olsson, M.; Ross, J. R. H.; J. Catal. 1999, 187, 493.

54. Jen, H. W.; Catal. Today 1998, 42, 37.

55. Acke, F.; Skoglundh, M.; Appl. Catal., B 1999, $20,133$.

56. Shimizu, K.; Maeshima, H.; Satsuma, A.; Hattori, T.; Appl. Catal., B 1998, $18,163$.

57. Konsolakis, M.; Yentekakis, I. V; J. Catal. 2001, $198,142$.

58. Burch, R.; Breen, J. P.; Meunier, F. C.; Appl. Catal., B 2002, 39, 283.

59. Armor, J. N.; Catal. Today 1995, 26, 99.

60. Iwamoto, M.; Hamada, H.; Catal. Today 1991, 10, 57.

61. Iwamoto, M.; Tahiro, H.; Catal. Today 1994, 22, 5
62. Cheung, T.; Bhargava, S. K.; Hobday, M.; Foger, K.; J. Catal. 1996, 158, 301.

63. Shelef, M.; Chem. Rev. 1995, 95, 209.

64. Amiridis, M. D.; Zhang, T.; Farruato, R. J.; Appl. Catal., B 1996, 10, 203.

65. Schay, Z.; James, V. S.; Pál-Borbély, G.; Beck, A.; Ramaswaruy, A. V.; Guczi, L.; J. Mol. Catal. A: Chem. 2000, 162, 191.

66. Yogo, K.; Ihara, M.; Tanaka, S.; Hishiki, I.; Kikuchi, E.; Chem. Lett. 1992, 1025

67. Hamada, H.; Kintaichi, Y.; Inaba, M.; Catal. Today 1996, 29, 53

68. Ueda, A.; Oshima, T.; Haruta, M.; Appl. Catal., B 1997, 12, 81.

69. Obuchi, A.; Ohi, A.; Nakamura, M.; Ogata, A.; Mizuno, K.; Ohuchi, H.; Appl. Catal., B 1993, 2, 71.

70. Odenbrand, C. U. I.; Blanco, J.; Avila, P.; Knapp, C.; Appl. Catal., B 1999, 23, 37.

71. Burch, R.; Millington, P. J.; Walter, A. P.; Appl. Catal., B 1994, 4, 65

72. Burch, R.; Watling, T. C.; Appl. Catal., B 1997, 13, 1.

73. Tanaka, T.; Yokota, K.; Isomura, N.; Doi, H.; Sugiura, M.; Appl. Catal., B 1998, 16, 199

74. Denton, P.; Giroir-Fendler, A.; Schnurman, Y.; Praliand, H.; Mirodatos, C.; Primet, M.; Appl. Catal., A 2001, 220, 141.

75. Shibata, J.; Shimizu, K.; Satsuma, A.; Hattori, T.; Appl. Catal., B 2002 37, 197.

76. Cataluña, R.; Baibich, I.; Dallago, R.; Piccinini, C. A.; Martínez-Arias, A.; Soria, J.; Quim. Nova 2001, 24, 55.

77. Agrofiotis, C.; Tsetsekon, A.; Stournaras, C. J.; Julbe A.; Dalmazio, L.; Guizard, C.; Solid State Ionics 2000, 136/137, 1301.

78. Bethke, K. A.; Kung, H. H.; J. Catal. 1997, 172, 93.

79. Park, P. W.; Ragle, C. S.; Boyer, C. L.; Balmer, M. L.; Engelhard, M.; McCready, D.; J. Catal. 2002, 210, 97.

80. Miyadera, T.; Appl. Catal., B 1993, 2, 199.

81. Miyadera, T.; Yoshida, K.; Chem. Lett. 1993, 1483

82. Hoost, T. E.; Kudla, R. J.; Collins, K. M.; Chattha, M. S.; Appl. Catal., B 1997, 13, 59.

83. Iglesias-Juez, A.; Hungria, A. B.; Martínez-Arias, A.; Fuerte, A.; FernándezGarcia, M.; Anderson, J. A.; Conesa, J. C.; Soria, J.; J. Catal. 2003, 217, 310

84. Miyadera, T.; Appl. Catal., B 1998, 16, 155.

85. Furusawa, T.; Lefferts, L.; Seshan, K.; Aika, K.; Appl. Catal., B 2003, 42, 25.

86. Yan, J.; Kung, M. C.; Sachtler, W. M. H.; Kung, H. H.; J. Catal. 1997, $172,178$.

87. Kung, M. C.; Bethke, I. C. A.; Yan, J.; Lee, J. H.; Kung, H. H.; Appl. Surf. Sci. 1997, 121, 261

88. Seker, E.; Cavataio, J.; Gulari, E.; Lorpongpaiboon, P.; Osuwan, S.; Appl. Catal., A 1999, 183, 121.

89. Meunier, F. C.; Ukropec, R.; Stapleton, C.; Ross, J. R. H.; Appl. Catal., B 2001, 30, 163

90. Meunier, F. C.; Zuzaniuk, V.; Breen, J. P.; Olsson, M.; Ross, J. R. H.; Catal. Today 2000, 59, 287.

91. Shimizu, K.; Kawabata, H.; Satsuma, A.; Hattori, T.; J. Phys. Chem. B 1999, $103,5240$.

92. Lombardo, E. A.; Sill, G. A.; d'Itri, J. L.; Hall, W. K.; J. Catal. 1998, 173, 440.

93. Obuchi, A.; Wogerbauer, C.; Koppel, R.; Baiker, A.; Appl. Catal., B 1998, 19,9

94. Poignant, F.; Saussey, J.; Lavalley, J. C.; Mabilon, G.; Catal. Today 1996, 29, 93.

95. Smith, J.; Phillips, J.; Graham, A.; Steele, R.; Redondo, A.; Coons, J.; J. Phys. Chem. A 1997, 101, 9157.

96. Bosch, H.; Janssen, F.; Catal. Today 1988, 2, 369.

97. Sumiya, S.; He, H.; Abe, A.; Takezawa, N.; Yoshida, K.; J. Chem. Soc., Faraday Trans. 1998, 94, 2217. 